
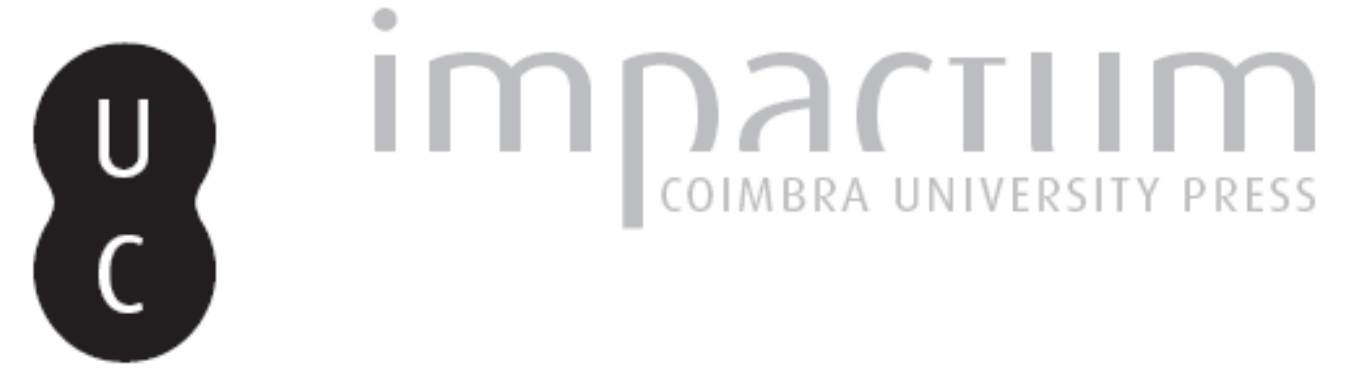

\title{
O planeamento de emergência de protecção civil em Portugal
}

Autor(es): $\quad$ Fonseca, Teresa Cravo da; Mendes, José Manuel

Publicado por: Associação Portuguesa de Riscos, Prevenção e Segurança

URL persistente:

URI:http://hdl.handle.net/10316.2/35835

DOI:

DOI:http://dx.doi.org/10.14195/1647-7723_20_2

Accessed : $\quad$ 26-Apr-2023 12:06:18

A navegação consulta e descarregamento dos títulos inseridos nas Bibliotecas Digitais UC Digitalis, UC Pombalina e UC Impactum, pressupõem a aceitação plena e sem reservas dos Termos e Condições de Uso destas Bibliotecas Digitais, disponíveis em https://digitalis.uc.pt/pt-pt/termos.

Conforme exposto nos referidos Termos e Condições de Uso, o descarregamento de títulos de acesso restrito requer uma licença válida de autorização devendo o utilizador aceder ao(s) documento(s) a partir de um endereço de IP da instituição detentora da supramencionada licença.

Ao utilizador é apenas permitido o descarregamento para uso pessoal, pelo que o emprego do(s) título(s) descarregado(s) para outro fim, designadamente comercial, carece de autorização do respetivo autor ou editor da obra.

Na medida em que todas as obras da UC Digitalis se encontram protegidas pelo Código do Direito de Autor e Direitos Conexos e demais legislação aplicável, toda a cópia, parcial ou total, deste documento, nos casos em que é legalmente admitida, deverá conter ou fazer-se acompanhar por este aviso.

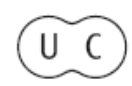




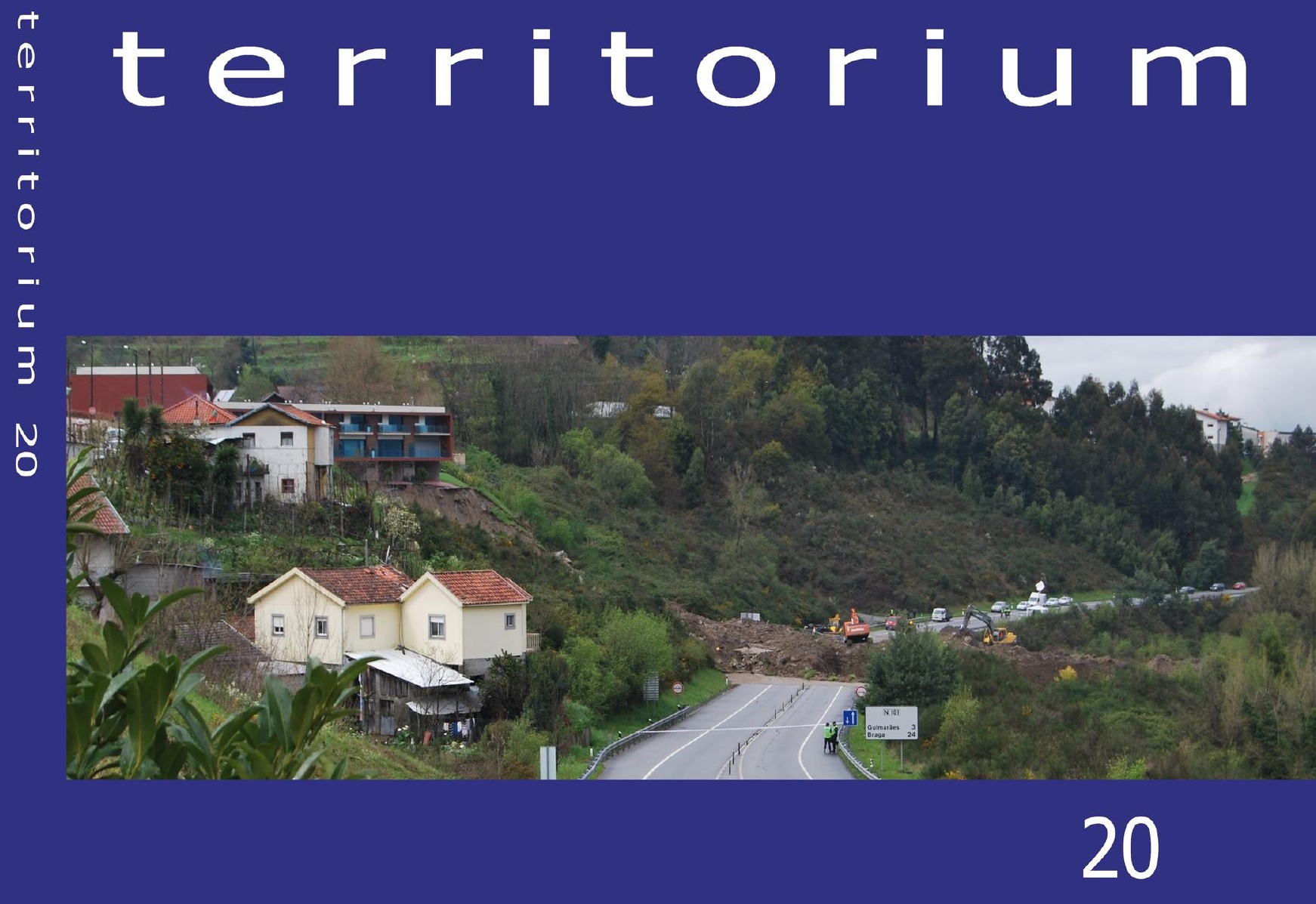

Riscos, População e Segurança 
Teresa Cravo da Fonseca

Instituto de Geografia e Ordenamento do Território, Universidade de Lisboa fonsecateresa80@gmail.com

José Manuel Mendes

Faculdade de Economia, Universidade de Coimbra jomendes@fe.uc.pt

\section{RESUMO}

Com a introdução em 2008 de novas alterações legislativas no âmbito do quadro dos critérios e normas técnicas para a elaboração e operacionalização de planos de emergência de protecção civil, foi proposto um novo paradigma de planeamento de emergência e uma nova estratégia de âmbito nacional. Com base em entrevistas aprofundadas a técnicos, operacionais, dirigentes, ex-dirigentes e investigadores envolvidos no processo, procede-se a uma análise crítica e reflexiva sobre o processo de implementação da "segunda geração" de planos de emergência de protecção civil.

Palavras-chave: Planeamento de emergência, protecção civil, paradigma, Portugal.

\section{RESUMEN}

Planificación de emergencia de protección de civil en Portugal - Con la introducción en 2008 de los nuevos cambios legislativos en el marco de las normas técnicas y criterios para el desarrollo y el funcionamiento de los planes de emergencia para la protección civil, conceptualiza un nuevo paradigma para la planificación de emergencia, una nueva estrategia nacional. Basado en el análisis de los gerentes técnicos, operacionales, ex gerentes e investigadores involucrados en el proceso, se establece un conjunto de variables dirigidas a un análisis reflexivo y reflexivo sobre el proceso de implementación de la " 2 a generación" de los planes de contingencia para proteger civil.

Palabras clave: Planificación de emergencia, protección civil, paradigm, Portugal.

\section{RÉSUMÉ}

Protection civile plan d'urgence au Portugal- Avec l'introduction en 2008 de nouvelles modifications législatives dans le cadre des normes et critères techniques pour le développement et le fonctionnement des plans d'urgence pour la protection civile, conceptualise un nouveau paradigme pour la planification d'urgence, une nouvelle stratégie nationale. Basé sur l'analyse des techniques, des responsables opérationnels, des gestionnaires anciens et chercheurs impliqués dans le processus, établit un ensemble de variables visant à une analyse réfléchi et réflexif sur le processus de mise en œuvre du «2e génération» des plans d'urgence pour protéger civile.

Mots-clé: Planification d'urgence, protection civile, paradig, Portugal.

\section{ABSTRACT}

Emergency planning of civil protection in Portugal - With the introduction in 2008 of new legislative changes within the framework of technical standards and criteria for the development and operation of emergency plans for civil protection, conceptualizes up a new paradigm for emergency planning, a new national strategy. Based on analysis of technical, operational managers, former managers and researchers involved in the process, draws up a set of variables aimed at an analysis reflective and reflexive about the process of implementing the "2nd generation" of contingency plans to protect civil.

Keywords: Emergency planning, civil protection, paradigm, Portugal.

\footnotetext{
* O texto deste artigo corresponde à comunicação apresentada ao VII Encontro Nacional de Riscos e I Forum ISCIA, tendo sido submetido para revisão em 05-11-2012, e aceite para publicação em 12-11-2012.

Este artigo é parte integrante da Revista Territorium, n. ${ }^{\circ} 20,2013,{ }^{\circ}$ RIscos, ISBN: 0872- 8941.
} 


\section{Introdução}

0 presente artigo decorre do trabalho de investigação desenvolvido no âmbito da dissertação de mestrado em Ciências do Risco, defendida na Faculdade de Economia da Universidade de Coimbra.

A alteração do quadro legal da actividade de protecção civil em 2006 projectou um quadro de mudança nas acções de planeamento de emergência. Com a introdução em 2008 de novas alterações legislativas no âmbito do quadro dos critérios e normas técnicas para a elaboração e operacionalização de planos de emergência de protecção civil, assistiu-se ao emergir de um novo paradigma de planeamento de emergência e a uma nova estratégia de nível nacional com reflexos marcantes para o nível municipal. Dos resultados obtidos, destacamse as seguintes conclusões: urgia implementar prazos ao processo; vinculá-los através da consulta pública e da publicitação em Diário da República; configurase o conhecimento técnico-científico do risco e dáse primazia à interligação com outros instrumentos de planeamento do território e de emergência; a matriz desta nova geração de planos é marcadamente operacional; promove-se a uniformização dos planos de protecção civil e investe-se no acompanhamento através de cadernos e guias técnicos. Contudo, o processo fragiliza-se pela cultura topdown; por princípios como o da informação estarem sonegados através da reserva do plano na componente do risco; o processo de aprovação é pouco expedito; a reduzida taxa de implementação desta matriz atrasa os processos a nível distrital e nacional; a matriz dá primazia às partes complementares, abandonam-se procedimentos, conceitos e estratégias; há muitas incertezas e dificuldades em implementar a nova matriz por parte dos municípios; os entrevistados reclamam um maior sentido prático e de boas práticas de esclarecimento.

\section{Metodologia}

Os dados analisados e discutidos no presente artigo foram recolhidos a partir de entrevistas aprofundadas e semiestruturadas. Foram realizadas um total de onze entrevistas. A escolha dos entrevistados partiu da definição de um público diversificado, procurando obter, através de linhas de raciocínio diferenciadas, a construção de ideias que conduzissem à compreensão da mudança de paradigma e da sua capacidade de implementação. Deste modo, foram seleccionados técnicos da ANPC/CDOS, comandantes distritais, técnicos da Protecção Civil, investigadores na área da protecção pivil e ex-dirigentes dos serviços de protecção civil.

Foi construído um guião de entrevista do tipo semiestruturada, assente nos seguintes princípios: garantir que vários participantes respondessem às mesmas questões; não haver uma ordem rígida nas questões; que o desenrolar da entrevista se adaptasse ao entrevistado e que permitisse um elevado grau de flexibilidade na exploração das questões. O guião foi construído incidindo em três grupos temáticos: caracterização do entrevistado; comparação da lei de bases; comparação das directivas. O guião não foi, contudo, aplicado na totalidade a todos os entrevistados, estando limitado às características profissionais de cada entrevistado. Refira-se deste modo que a parte três foi apenas aplicada a técnicos e operacionais que desenvolvem a sua actividade na área do planeamento de emergência de protecção civil.

No que diz respeito ao processo de análise de conteúdo das entrevistas a metodologia adoptada segue a orientação de um conjunto de autores. Godor (1995) e SILvA et al. (2004) são citados por BARDIN (2009), na utilização da análise de conteúdo seguindo três fases fundamentais:

- a pré-análise: implica a organização do material, quer dizer de todos os materiais utilizados para a colecta dos dados, assim como outros materiais que podem ajudar a entender melhor o fenómeno e fixar o que o autor define como corpus da investigação, que seria a especificação do campo que o pesquisador deve centrar a atenção.

- a descrição analítica: nesta etapa o material reunido que constitui o corpus da pesquisa é mais bem aprofundado, sendo orientado em princípio pelas hipóteses e pelo referencial teórico, surgindo desta análise quadros de referências, buscando sínteses coincidentes e divergentes de ideias.

- interpretação referencial: é a fase de análise propriamente dita. A reflexão, a intuição, com base em materiais empíricos, estabelecem-se relações com a realidade aprofundando as conexões das ideias, chegando se possível à proposta básica de transformações nos limites das estruturas específicas e gerais.

Segundo Guerra (2006), a análise categorial prevê a identificação de variáveis cuja dinâmica é potencialmente explicativa de um fenómeno que queremos explicar, utilizado quando na mesma entrevista se podem encontrar vários factores explicativos e nenhum dos discursos dos entrevistados conter todos as variáveis. Assim, é uma análise que faz a mediação para uma explicação e para a construção ideal típica.

\section{O Planeamento de Emergência em Protecção Civil em Portugal}

\section{Enquadramento legislativo}

O planeamento de emergência de protecção civil assenta hoje na Resolução da Comissão Nacional de Protecção 
Civil $n^{\circ} 25 / 2008$, de 18 de Julho. É um instrumento criado no âmbito da definição dos critérios e normas técnicas sobre a elaboração de planos de emergência.

Com o previsto na alínea $\mathrm{h}$ ) do $\mathrm{n} .{ }^{\circ} 2$ do artigo $36 .{ }^{\circ}$ e no $\mathrm{n} .{ }^{\circ}$ 1 do artigo $50 .^{\circ}$, ambos da Lei de Bases de Protecção Civil - Lei n 27/2006, de 3 de Julho, a Comissão Nacional de Protecção Civil emanou, através da referida Resolução, as directivas relativas à definição dos critérios e normas técnicas sobre a elaboração de planos de emergência.

Assim, nos termos e ao abrigo do disposto nos n.os 1 e 2 do artigo $7 .^{\circ}$ da Portaria n. ${ }^{\circ} 302 / 2008$, de 18 de Abril, a Comissão Nacional de Protecção Civil, em reunião realizada em 16 de Abril de 2008, deliberou:

1) Aprovar a directiva relativa aos critérios e normas técnicas para a elaboração e operacionalização de planos de emergência de protecção civil, que constitui anexo à presente resolução, da qual faz parte integrante;

2) Revogar a directiva para a elaboração de planos de emergência de protecção civil publicada, através de declaração do Gabinete do Ministro da Administração Interna, no Diário da República, $2 .{ }^{a}$ série, n. ${ }^{\circ} 291$, de 19 de Dezembro de 1994.

Iniciou-se, deste modo, uma nova etapa para os designados "nova geração de planos de emergência de protecção civil”.

Toda esta estratégia de planeamento de emergência é sustentada por uma reformulação do quadro legislativo de protecção civil, destacando-se: a Lei n 27/2006, de 3 de Julho - Lei de Bases da Protecção Civil; a Lei $n^{\circ}$ 65/2007, de 12 de Novembro - Enquadramento institucional e operacional da protecção civil no âmbito municipal, organização dos serviços municipais de protecção civil e competências do comandante operacional municipal; e o Decreto-Lei n 134/2006, de 25 de Julho - Sistema Integrado de Operações de Protecção e Socorro (SIOPS).

Admitindo-se o surgir de um novo quadro de mudança na área do planeamento de emergência há uma sinergia que fomenta esta mudança. É objectivo do novo quadro legislativo promover uma maior interligação entre os mecanismos de planeamento de emergência de protecção civil e os instrumentos de planeamento e ordenamento do território. Segundo a Resolução da Comissão Nacional de Protecção Civil $n^{\circ} 25 / 2008$, de 18 de Julho, "essa interligação visa o estabelecimento de sinergias ao nível da identificação de riscos e vulnerabilidades e da harmonização de bases cartográficas, considerando-se que os planos de emergência de protecção civil devem seguir o disposto no decreto regulamentar que fixa a cartografia a utilizar nos instrumentos de gestão territorial."
Assim, este objectivo foi concretizado através dos processos de revisão dos Planos Directores Municipais (PDM) e dos Planos Municipais de Emergência (PME), criando-se as condições para fomentar mudanças na gestão do planeamento territorial.

A evolução do paradigma de planeamento de emergência

Segundo a Resolução da Comissão Nacional de Protecção Civil n 25/2008, de 18 de Julho, os planos de emergência de protecção civil são documentos formais nos quais as autoridades de protecção civil, nos seus diversos níveis, definem as orientações relativamente ao modo de actuação dos vários organismos, serviços e estruturas a empenhar em operações de protecção civil.

Tais planos tinham sido, até à implementação do novo quadro legal, elaborados de acordo com o disposto na directiva para a elaboração de planos de emergência de protecção civil, aprovada pela Comissão Nacional de Protecção Civil (CNPC) em 1994, importando proceder à actualização deste documento para o adequar ao novo enquadramento legal do Sistema de Protecção Civil, tomando em linha de consideração as boas práticas existentes no domínio da elaboração e operacionalização de planos de emergência de protecção civil.

Esta nova alteração legislativa, que compõe uma revisão dos anteriores planos de emergência de protecção civil, veio estabelecer uma maior interligação entre os mecanismos de planeamento de emergência de protecção civil e os instrumentos de planeamento e ordenamento do território.

As novas orientação visavam ainda, potenciar o estabelecimento de sinergias ao nível da identificação de riscos e vulnerabilidades e da harmonização de bases cartográficas. De facto, no âmbito das bases cartográficas, trouxe ainda uma forte mudança na regulamentação da cartografia e nos instrumentos a utilizar na gestão territorial e na sua implementação nos planos de emergência de protecção civil

Por outro lado, clarificou-se o acesso público aos planos de emergência e garantiu-se a disponibilização das suas componentes não reservadas em plataformas baseadas nas tecnologias de informação e comunicação, promovendo a interacção com o cidadão. Esta nova estratégia poderá permitir um maior grau de participação, responsabilização e acompanhamento das medidas adoptadas e uma maior proximidade aos diversos agentes de protecção civil.

A obrigatoriedade de os planos de emergência serem disponibilizados em formato digital, devidamente acompanhados de uma base de dados de meios e recursos e de um sistema de informação geográfica, reverte para uma das mudanças fulcrais das novas obrigações legais, 
isto é, o potenciar das novas tecnologias, facilitando a rápida e permanente actualização e reforçando o planeamento de emergência em Portugal.

Por último, com a referida directiva, normalizou-se a estrutura e os conteúdos dos planos de emergência, agilizando o seu processo de elaboração, revisão e aprovação e introduzindo mecanismos de verificação periódica da sua eficácia.

Planeamento de emergência: percepções da emergência do novo paradigma

\section{Planeamento de emergência}

\section{Definição de planeamento de emergência}

Os entrevistados foram questionados sobre qual a sua definição de planeamento de emergência. Em termos conceptuais o termo conhecimento e a justaposição entre plano e planeamento foram sustentadas pelos argumentos dos entrevistados (fig. 1). Alguns entrevistados associam o planeamento de emergência ao conceito conhecimento, refutando através dos seus discursos que a ciência, o enquadramento territorial, o conhecimento sobre o sistema e as competências dos agentes de protecção civil sejam fulcrais para o sucesso do planeamento de emergência. Para alguns entrevistados definir este conceito é contrapô-lo com um outro, o de plano. Assim, surgem os argumentos para a noção de plano em contraponto com a noção de planeamento. O plano é enunciado como o documento resultante, planeamento definido como processo, ambos imersos em diretrizes, regras, procedimentos e acções que emergem de um elemento comum, a actualização dos planos de emergência.

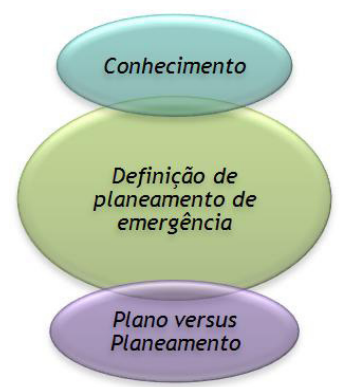

Fig. 1 - Definição de planeamento de emergência.

\section{O paradigma de planeamento de emergência}

Pediu-se aos entrevistados que fizessem uma análise comparativa do paradigma de planeamento de emergência, analisando aquilo que era o antigo e o que é o novo quadro legislativo que o regula. Das respostas dos entrevistados surgiram dois conceitos: a evolução e a aplicação (fig. 2). Os entrevistados reforçam que há um quadro de evolução, evolução esta que se configura não só num aumento de número de planos de emergência de protecção civil, mas também numa evolução no quadro conceptual, atribuindo maior rigor ao processo. Contudo, numa concepção global, alguns entrevistados retratam esta evolução como uma readequação do modelo anterior, que implicou a aplicação das novas orientações. Orientações retratadas como mais operacionais, mais estritas, mais articuladas mas que em certo ponto poderão colocar em causa a eficácia e a eficiência do plano, por torná-lo tão rígido na sua matriz.



Fig. 2 - Paradigma do planeamento de emergência.

\section{Tipificação dos Planos}

Foi pedido aos entrevistados que falassem sobre a lógica da tipificação dos planos. Da análise feita, obteve-se dois conceitos: indefinição e hierarquia (fig. 3). Os entrevistados consideram que há uma certa indefinição na tipificação, há uma confusão generalizada por toda a legislação, em que designações como planos de prevenção, planos prévios de intervenção, planos especiais e planos gerais surgem sem consagrar, na maioria da vezes, uma definição conceptual clara, bem como a sua estratégia de articulação. Geram-se, assim, constrangimentos na aplicação dos planos de emergência, na articulação ou na hierarquia dos níveis analíticos, bem como na distinção entre planos com géneses distintas (protecção civil, higiene e segurança no trabalho, saúde, por exemplo). Os entrevistados referiram-se ainda, com maior pormenor, acerca da hierarquia dos planos, onde se identifica a ausência da referência à articulação entre o planeamento interno e o externo de emergência, a indefinição de hierarquia entre planos de protecção civil, avocando que deveriam funcionar em sinergia uns com os outros. Segundo os entrevistados, esta lacuna está presente em grande parte do quadro legislativo aplicável ao planeamento de emergência.

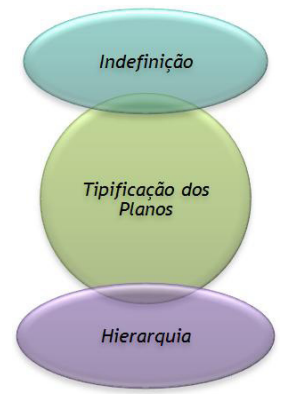

Fig. 3 - Tipificação dos Planos. 


\section{Elaboração dos planos}

No que diz respeito à elaboração dos planos, os entrevistados foram questionados sobre 0 seu relacionamento institucional com a tutela. Das respostas obtidas configuraram-se três perspectivas: relacionamento adequado parcialmente, bottom-up e outsourcing (fig. 4). A adequação parcial prendia-se com o nível distrital, que seria o que se configurava como menos adequado, facto devido à tutela do governador civil, figura institucional entretanto desaparecida do quadro administrativo português. Por outro lado, alguns entrevistados consideram que a estratégia de elaboração prevê uma estratégia bottom-up, tendo os entrevistados alguma dificuldade em reconhecer o papel dos planos gerais de nível distrital e defendendo alguns que o plano geral nacional deveria ter sido o primeiro a ser elaborado para que servisse de referencial ao país. No que diz respeito ao processo de elaboração dos planos, muitos dos entrevistados referiram-se à opção de outsourcing, verificada em grande escala nesta fase. Segundo os entrevistados, esta opção de outsourcing afiguravase como prejudicial para a qualidade dos planos mas necessária, tendo em conta a falta de recursos humanos especializados e o factor urgência manifestado em alguns casos.

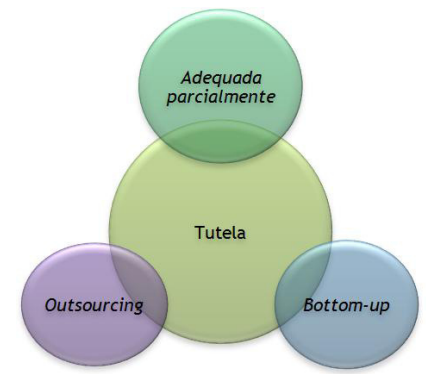

Fig. 4 - Tutela de elaboração dos planos.

Aprovação dos planos

Foi pedida a opinião aos entrevistados sobre a aprovação dos planos aos vários níveis territoriais. Distinguiramse duas linhas de orientação contidas nas respostas dos entrevistados: aplicação e uniformização (fig. 5). No que concerne à aplicação, os entrevistados eram da opinião que a competência atribuída à Comissão Nacional de Proteção Civil (CNPC) pode constituir um entrave à celeridade e à qualidade do processo. Contudo, os entrevistados reforçam que era fundamental elevar este procedimento à escala nacional, como forma de garantir a uniformidade dos planos. Neste sentido referem a Autoridade Nacional de Protecção Civil (ANPC) como a entidade que deveria garantir este procedimento de uniformização. Foram ainda levantadas dúvidas sobre a legitimidade da tutela de âmbito regional (Regiões Autónomas dos Açores e da Madeira), que fica centrada nos Governos Regionais, alegando que este procedimento não garante a uniformidade perante o Continente. Neste sentido, identificou-se no discurso dos entrevistados um enfoque no conceito da uniformização, defendido numa posição bilateral. O processo deveria ser estabilizado de forma uniforme, mas os entrevistados reconhecem que num país com realidades diversas como é Portugal, é irracional exigir planos com matrizes rígidas.

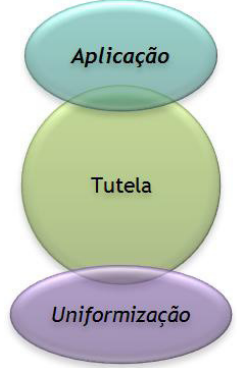

Fig. 5 - Tutela de aprovação dos planos.

Publicitação dos planos: procedimentos de consulta pública

Identificando uma nova dinâmica sobre a publicitação dos planos de emergência, questionou-se aos entrevistados se consideravam os procedimentos de consulta pública e de publicitação no Diário da República (DR) como uma garantia para a qualidade do planeamento de emergência. Das respostas obtidas ponderaram-se três conceitos de análise: mais-valia, eficácia e informação reservada (fig. 6). No que concerne aos conceitos de mais-valia e de eficácia, os entrevistados concordaram que o processo de consulta pública promove a participação pública, ainda que alguns defendam que por si só não é eficaz, pois carece de outras estratégias complementares que traduzam a linguagem de protecção civil, que aproximem o cidadão ao processo. Quanto à sua publicitação em $\mathrm{DR}$, consideraram que o mesmo confere legalidade ao plano, vinculando o cidadão e permitindo uma execução mais eficaz do plano. Relativamente a este processo os entrevistados referiram-se ao facto de muitos planos terem informação confidencial, opinando que reservar componentes do plano como a caracterização do território e a identificação dos riscos não só entra em incumprimento com o princípio da informação, plasmado na Lei de Bases de Protecção Civil, como é ineficaz, pois estas informações acabam por ser divulgadas por outros documentos, nomeadamente os Planos Directores Municipais (PDM). Consideram, assim, que as componentes confidenciais deveriam ser melhor selecionadas.

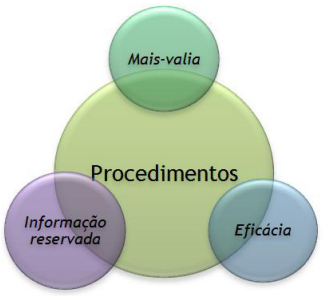

Fig. 6 - Procedimentos de consulta pública e publicitação em Diário da República. 


\section{Articulação dos planos}

No processo de estabelecer estratégias de articulação entre os planos de emergência e os de ordenamento do território questionou-se sobre a viabilidade desta premissa, e que estratégias estavam a ser adoptadas. Os entrevistados reúnem as suas ideias num conceito que se considerou igual para ambos os temas em análise: a aplicação (fig. 7). No que toca aos Planos de Emergência (PE), para os entrevistados este processo ainda se encontra pouco desenvolvido, tendo em conta que um elevado número de planos se encontravam em revisão e com ritmos temporais de elaboração e revisão diferenciados. Muitos dos entrevistados defenderam que o nível distrital devia fomentar a articulação entre municípios, tendo em conta que se aplicou ao processo de articulação uma estratégia bottom-up, havendo uma clara necessidade de integração do processo nas várias escalas. Alguns entrevistados referem, contudo, algumas dificuldades em identificar as esferas em que se pretende esta articulação. Relativamente aos Planos de Ordenamento do Território, os entrevistados consideraram que a articulação ainda é frágil, os planos estão em fases diferentes de elaboração e para alguns municípios essa articulação só será possível numa fase posterior do processo.

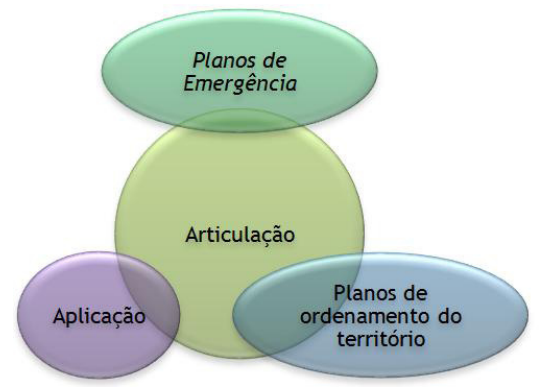

Fig. 7 - Articulação entre planos de emergência.

\section{Revisão dos planos}

Tendo sido determinados prazos para a aplicação da nova resolução, bem como para a revisão do plano, questionouse os entrevistados sobre os timings estabelecidos pelos vários instrumentos legislativos (fig. 8 e 9).

\section{Cumprimento de aplicação da nova directiva}

Os entrevistados consideraram que era fundamental estipular-se um prazo de execução, sendo da opinião, contudo, que os prazos estabelecidos não respeitaram a realidade municipal. A reformulação da matriz de análise exigiria a existência de quadros técnicos e recursos humanos que suplantavam a capacidade de resposta de alguns serviços municipais de proteção civil, muitos acabando por fazer concessões para a sua elaboração. Foi ainda defendido por alguns entrevistados que o estabelecer de um prazo para aplicação de uma directiva não garante o seu cumprimento, tendo em conta que não se fomentou uma estratégia de promoção para os municípios cumpridores e uma penalização para os não cumpridores. Foi ainda mencionado que esta meta se traduziu "numa imagem de menoridade que os municípios têm perante a administração central”, tendo em conta que os prazos apenas foram estipulados para os municípios e não para as entidades reguladoras.



Fig. 8 - Cumprimento da aplicação da nova directiva.

\section{Prazos de revisão e actualização dos planos}

Alguns entrevistados consideram que os prazos estabelecidos devem apenas servir de referencial, defendendo que o plano deve estar em constante atualização. Advogaram mesmo que cumprir o processo de dois em dois anos só implicará uma elevada carga burocrática, pondo mesmo em causa a capacidade de resposta da Autoridade Nacional de Protecção Civil (ANPC) em atribuir pareceres nos prazos estipulados. Contudo, outros defendem que sem este referencial temporal se correria o risco de prolongar situações em que os municípios não atualizavam os seus planos de emergência há mais de dez anos. Alguns entrevistados foram da opinião que esta atualização segue regras estabelecidas, não se exigindo que o documento seja atualizado na totalidade, salvaguardando apenas a integração das alterações mais significativas verificadas no território sobre o qual incide o plano de emergência.

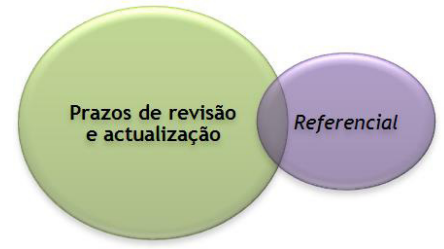

Fig. 9 - Prazos de revisão e actualização.

\section{Distribuição extensiva}

Naquilo que é a estratégia de distribuição extensiva e a utilização de suportes de tecnologia de informação e de comunicação, questionou-se aos entrevistados se concordavam com esta distribuição, e se o acto de distribuição era suficiente para configurar o sucesso de planeamento de emergência. Das respostas obtidas há duas análises conceptuais a fazer: estratégia insuficiente e cumprimento de formalidade (fig. 10). Os entrevistados partilharam que consideram a estratégia insuficiente da forma como está definida, sendo 
necessário encontrar outras estratégias e ferramentas complementares que melhorem o mecanismo de informação, comunicação e sensibilização sobre as acções de protecção civil e riscos, defendendo que além de divulgar os planos é preciso explicar os mesmos. Os entrevistados consideraram ainda que este é um mero cumprimento das formalidades exigidas, configurando-se como uma forma de legitimação dos planos de emergência, pois ao se definir uma estratégia de distribuição as entidades envolvidas ficam claramente vinculadas ao plano.

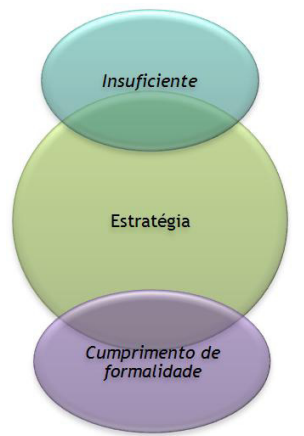

Fig. 10 - Estratégia de distribuição.

\section{Matriz de planeamento}

\section{Caracterização}

Os entrevistados foram questionados quanto à matriz de planeamento. Das respostas obtidas classificamse dois parâmetros de análise: matriz técnica versus matriz operacional e a noção de que a matriz é equilibrada (fig. 11). No que toca ao conceito técnico versus operacional, os entrevistados referiram que a sua componente é forte no cariz operacional mas também compõe uma carga, considerada elevada, de aspectos técnicos. Para alguns entrevistados, a matriz deve ser operacional pois o seu objecto é preparar a resposta e a recuperação em caso de emergência. Contudo, segundo alguns entrevistados, perderam-se algumas rotinas e boas práticas que deveriam ter sido mantidas. Outros entrevistados consideraram a matriz como equilibrada referindo que ambas as vertentes, operacional e técnica, estão representadas na matriz de planeamento.

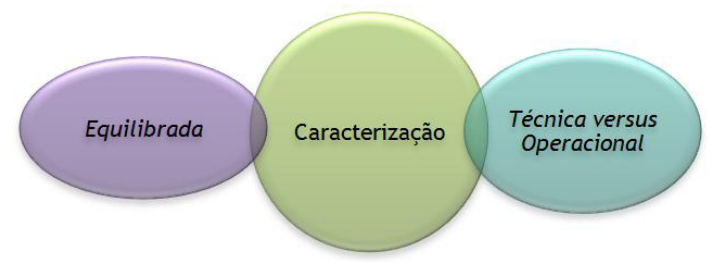

Fig. 11 - Caracterização da matriz.

\section{Estrutura do plano}

No que diz respeito à estrutura do plano e à proposta de índice questionou-se os entrevistados se os consideravam concretizáveis, e se respondiam à eficácia do levantamento das vulnerabilidades, da identificação dos riscos e na organização da resposta à emergência. No que diz respeito à caracterização da estrutura do plano surgiram na análise das respostas as seguintes categorias: fragilidades, inovações, eficiência e repetição (fig. 12). Alguns dos entrevistados afirmaram que a estrutura do plano tinha fragilidades: em alguns pontos não se respeitavam as rotinas que já existiam; existiam componentes do plano que promoviam a repetição e o excesso de informação; introduzem-se e misturavamse conceitos que não estavam ou bem definidos ou bem estabilizados; eram incorporadas estratégias operacionais e técnicas sem que se procedesse a um esclarecimento conceptual das mesmas. Contudo, alguns entrevistados reforçam que havia inovações: a aposta em estratégias de representação de informação (fluxogramas, organogramas, etc.) que vinham fomentar a clarificação do volume de informação constante do plano, bem como a implementação de uma estrutura menos pesada para a activação do plano.

O conceito de eficiência foi igualmente apreendido no discurso de alguns entrevistados, traduzido numa melhor estruturação e com enfoque claro no grande objectivo de qualquer plano de emergência que é a resposta. Esta nova estrutura permite identificar, segundo os entrevistados, com maior clareza a missão das entidades envolvidas e a sua articulação.



Fig. 1 L - Laracterızaçao da estrutura dos planos de emergência.

\section{Exercícios}

Avançando para o que se pode chamar o ponto de retorno do planeamento de emergência, os entrevistados foram questionados sobre a importância de se fazer exercícios, dos prazos estabelecidos para os planos serem testados e da importância de serem promovidas orientações para os executar (fig. 13, 14 e 15).

\section{Importância dos exercícios}

Analisando a questão da importância dos exercícios, foram consideradas, através das respostas obtidas, 
duas categorias: acto de estabelecimento de rotinas e fragilidades (fig. 13). Alguns entrevistados consideram os exercícios como actos para o estabelecimento de rotinas, onde se testam e melhoram procedimentos, transferindo-os para a execução de melhorias no planeamento e na certificação dos planos. Contudo, alguns entrevistados identificaram fragilidades para esta estratégia, referindo-os como estratégias falaciosas, pois na maioria das vezes são tão preparados que apenas geram os efeitos esperados, sendo muitas vezes utilizados para promover as entidades e não para ajudar a identificar as fragilidades no processo.

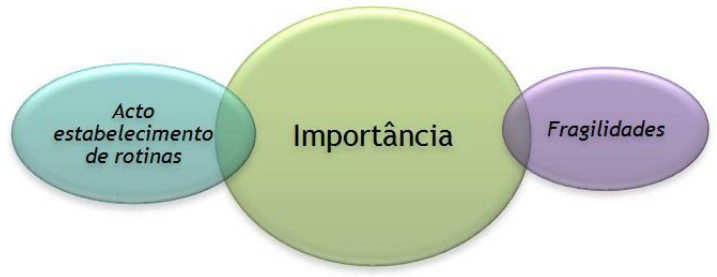

Fig. 13 - Importância dos exercícios.

\section{Prazos para teste dos planos}

No que toca aos prazos estabelecidos para se testar os novos planos de emergência, consideraram-se duas categorias: imprescindível e facultativo (fig. 14). Alguns entrevistados consideraram o prazo um acto imprescindível, considerando que se o mesmo não for estabelecido não existirá validação dos planos até uma próxima atualização. Muitos dos entrevistados foram da opinião de que o prazo de 180 dias não era exequível para alguns municípios, mesmo que se alternasse entre exercícios de gabinete (CPX) e no terreno (LIVEX). Houve entrevistados que defenderam que a realização de exercícios deveria ser facultativa, argumentando que devia ser o gestor a decidir o plano de exercícios. Para isso bastaria que a lei previsse esse acto como uma componente do planeamento de emergência.

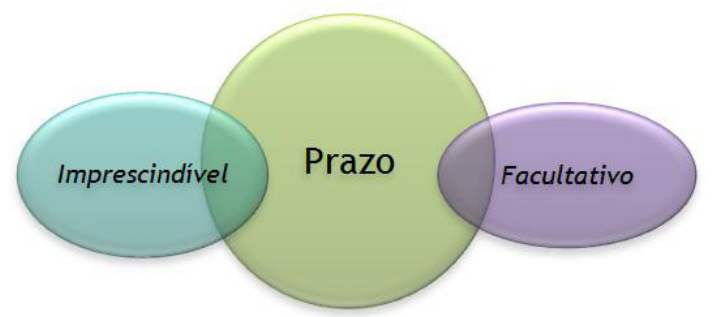

Ilustração 14 - Prazo para executar os exercícios.

Orientações para desenvolver os exercícios

Os entrevistados foram questionados sobre a necessidade de serem emanadas orientações para o desenvolvimento de exercícios, tentando aqui configurar as práticas actuais e futuras sobre este procedimento. Das respostas obtidas classificaram-se duas classes de resposta: fundamental e dispensável (fig. 15). Alguns entrevistados consideraram fundamental a existência de orientações, pois era necessário definir normas, regras e procedimentos que promovessem a uniformização da realização dos exercícios e a comparação dos seus resultados. Houve, contudo, alguns entrevistados que desvalorizaram a existência de orientações e as considerassem como mais um condicionamento à realização dos exercícios.

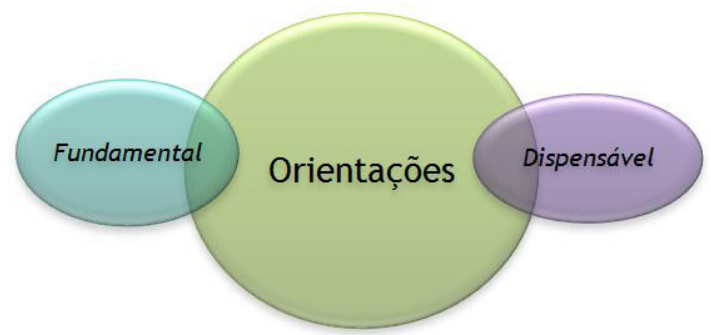

Fig. 15 - Orientações para desenvolver os exercícios.

\section{Orientações técnicas emitidas pela ANPC}

\section{Importância}

Por fim, foi solicitado aos entrevistados a sua opinião sobre as orientações técnicas emitidas como actos de apoio à concretização de novo quadro normativo. Das respostas obtidas, agregamos as respostas em duas vertentes: documentos normativos/referenciais e a sua aplicabilidade (fig. 16). Alguns entrevistados consideraram que era importante existirem documentos normativos/referenciais emitidos pela Autoridade (ANPC) para se poder fazer doutrina, devendo ser vistos como ferramentas de apoio, como meras orientações ao desenvolvimento do planeamento e não configurarem uma vinculação obrigatória. A publicação de alguns destes documentos permitiu aos entrevistados que se pronunciarem sobre a sua aplicabilidade. Alguns entrevistados consideram que as primeiras publicações (cadernos técnicos) surgiram tarde, que nem todos têm o mesmo nível de qualidade, mas que têm vindo a responder à definição de metodologias e padronização de procedimentos. Falta-lhes ainda uma divulgação mais direcionada aos técnicos, falta-lhes a sua explicação a sua aproximação ao nível que mais os utiliza, o nível municipal.

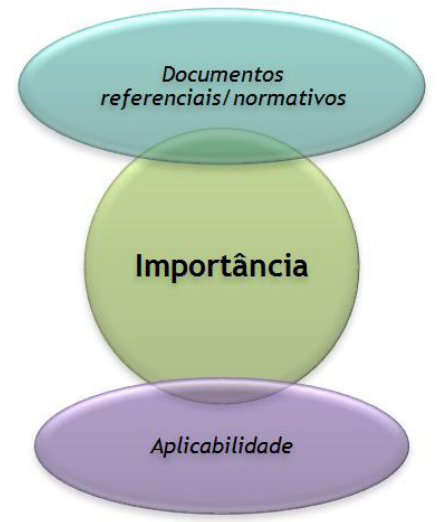

Fig. 16 - Importância das orientações técnicas emitidas pela ANPC. 


\section{Conclusão}

A alteração do quadro legal da actividade de protecção civil projectou um quadro de mudança nas acções de planeamento de emergência em Portugal. Esta regulamentação levou a que o níveis municipal, distrital e nacional de planeamento de emergência se reorganizassem para dar resposta a esta mudança. Entre o ano de 2006, que marca a mudança no quando geral da protecção civil, e o ano de 2008 em que é instituído um novo quadro na área do planeamento de emergência de protecção civil, promoveram-se um conjunto de alterações que marcariam o designado paradigma de planeamento de emergência.

Através dos contributos recolhidos pelas entrevistas realizadas a vários profissionais da protecção civil, podemos afirmar que há declaradamente um quadro de mudança e de reformulação do que estava anteriormente instituído. Contudo, foram identificados por vários entrevistados alguns entraves que podem pôr em causa a eficácia e a eficiência do processo. Identificaram-se falhas a nível do quadro conceptual de protecção civil, no esclarecimento das práticas e na concretização de uma estratégia top-down na definição das orientações em contraste com uma estratégia bottom-up na execução dos planos de emergência, dificultando por vezes o entendimento e a aplicação de determinadas estratégias.

Entre operacionais, técnicos, investigadores, dirigentes e ex-dirigentes há uma linha de raciocínio que vai unindo as várias reflexões recolhidas: é preciso reconhecer o valor do que já foi anteriormente implementado, envolver todos os actores no processo, esclarecer, comunicar e formar sobre o novo quadro a implementar. O paradigma, a deontologia, o quadro legal, o quadro técnico e o quadro operacional na área da protecção civil carecem de explicação, de divulgação e de suporte científico.

A actividade de protecção civil, que tem um carácter permanente, multidisciplinar e plurissectorial, aspectos consignados na lei de bases de protecção civil, necessita de ser fortalecida por alguns dos seus princípios estruturantes, a saber: a informação, a cooperação, a coordenação, a disseminação e a implementação pelo território onde se aplica, de forma a promover a participação esclarecida de todos os cidadãos na prevenção e na resposta de emergência.

\section{Referências bibliográficas}

FonseCA, Teresa (2010) - O Paradigma de Emergência de Protecção Civil em Portugal. Tese de dissertação de Mestrado. Faculdade de Economia da Universidade de Coimbra. (https://estudogeral.sib.uc.pt/jspui/ handle/10316/14572).

BARDIN, Laurence (2009) - Análise de Conteúdos. Edições 70. Lisboa.

Guerra, Isabel Carvalho (2006) - Pesquisa Qualitativa e Análise de Conteúdo - sentidos e formas de uso. Reimpressão Fevereiro de 2010. Princípia Editora, Lda. Cascais.

Silva, C. R.; GobBI, B. C.; SimÃo, A. A. (2004) - O uso da análise de conteúdo como uma ferramenta para a pesquisa qualitativa: descrição $e$ aplicação do método. Organ. rurais agroind., Lavras, v. 7, n. 1, p. 70-81.

\section{Entrevistas não confidenciais}

Almeida, Paula (2010) - Técnica Superior do Comando Distrital de Operações de Socorro de Setúbal. Palmela, 20 de Maio de 2010.

AmAro, António (2010) - Director da Escola Superior de Saúde de Alcoitão. Desenvolveu a sua tese de Doutoramento em "O Socorro em Portugal - Organização, formação e cultura de segurança nos corpos de bombeiros, no quadro da Protecção Civil.". Alcoitão, 19 de Maio de 2010.

Beıró, Cláudia (2010) - Coordenador do Serviço Municipal de Protecção Civil de Coimbra. Odivelas, 31 de Maio de 2010.

Esteves, Rui (2010) - Comandante Operacional Distrital do Comando Distrital de Operações de Socorro. Castelo Branco, 23 de Abril de 2010.

Ferreira, António (2010) - Consultor para a Protecção Civil de Mafra. Mafra, 29 de Junho de 2010

Jesus, Álvaro (2010) - Consultor para a Protecção Civil, Coordenador do SMPC do Seixal. Seixal, 1 de Setembro de 2010.

LoPES, Joana (2010) - Técnica Superior do Serviço Municipal de Protecção Civil de Coimbra. Coimbra, 24 de Maio de 2010.

Mendes, Carlos (2010) - Chefe do Grupo de Planeamento de Emergência na Autoridade Nacional de Protecção Civil. Carnaxide, 30 de Junho de 2010.

Ribeiro, Manuel João (2010) - Director do Departamento de Protecção Civil de Cascais. Cascais, 11 de Junho de 2010.

Velloso, Manuel (2010) - Presidente da Associação Nacional Dos Alistados Das Funções Sanitárias. Lisboa, 31 de Maio de 2010.

VieIRA, Victor (2010) - Director do Departamento de Protecção Civil de Lisboa. Lisboa, 1 de Junho de 2010. 